Primeiro semestre 2014, volume 1, número 16.

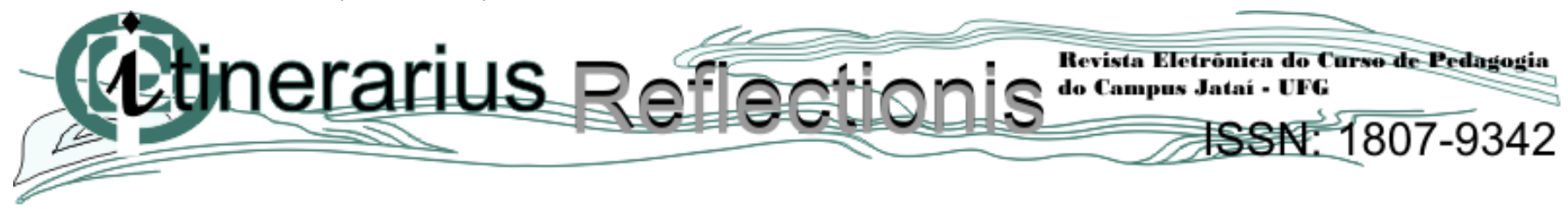

\title{
GEOGRAFIA, CIDADE E LUGAR NO PROCESSO DE ENSINO E APRENDIZAGEM: UM ENFOQUE A PARTIR DA CIDADE DE FORMOSA - GO
}

Hugo de Carvalho Sobrinho. Universidade Estadual de Goiás Unidade Universitária de Formosa E-mail: hugodecarvalho2009@hotmail.com

Rodrigo Capelle Suess. Universidade Estadual de Goiás Unidade Universitária de Formosa E-mail: rodrigo.capellesuess@hotmail.com

Rafael Gonçalves Bezerra Instituto Federal de Educação e Tecnologia Instituto Federal de Educação, Ciência e Tecnologia de Goiás

Câmpus Formosa E-mail: ra.fagonalves@hotmail.com

\begin{abstract}
RESUMO: Dialogar sobre a relação existente entre Geografia, cidade e lugar enriquece o processo de ensino-aprendizagem, considerando a cidade na qual residem os alunos como um palco para a produção do conhecimento. Assim, este trabalho tem como finalidade refletir sobre a importância da valorização da cidade e do espaço vivido pelo aluno no processo ensino-aprendizagem e averigua as concepções que educadores têm a respeito da cidade de Formosa-GO como palco da aprendizagem. A cidade de FormosaGO, com mais de 100.000 habitantes e 170 anos de história, com seus festejos, manifestações culturais e religiosas, com seus recursos naturais exuberantes, mas também, com problemas e situações peculiares de uma cidade que se desenvolve, detém locais que podem ser assumidos como uma sala de aula. Fazer da cidade uma proposta pedagógica é um desafio, porém necessário quando se quer partir do mundo vivido do discente para que a aprendizagem torne-se significativa. Explorar espaços que rodeiam a escola que são vistos pelos alunos do caminho de casa para escola leva as alunos a conhecerem, intervir e (re) criar a sua cidade.
\end{abstract}

Palavras-chave: Geografia. Cidade. Lugar. Ensino-aprendizagem.

ABSTRACT: Dialogue about the relationship between geography, city and place, values the teachinglearning process, considering the city in which the students reside as a stage for the production of knowledge. This work aims to reflect on the importance of valuing the city and lived space by the student in teaching-learning process and checks the conceptions that teachers have about the city Formosa-GO as a 


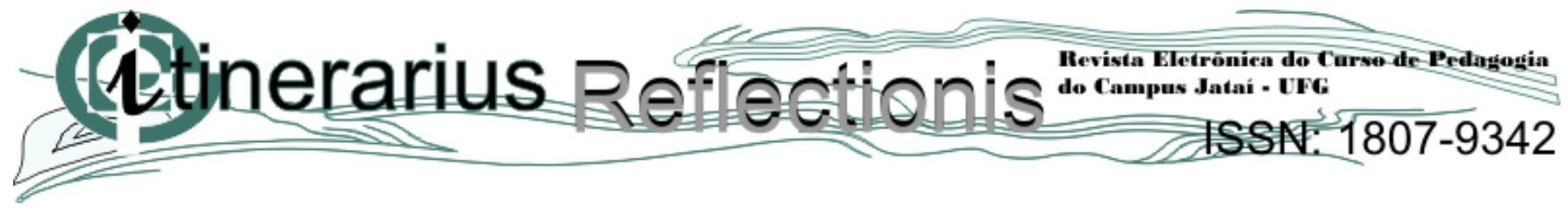

place of learning. The city of Formosa-GO, with more than 100.000 inhabitants and 170 years of history, with its festivities, cultural and religious manifestations, with its lush natural resources, but also with problems and situations peculiar of a city in growth, owns local that can be considered as classroom. Make the city a pedagogical proposal is a challenge, but necessary if one wants from the lived world of the student so that learning becomes meaningful. Explore spaces surrounding the school which are seen by the students of the way from home to school lead the students to know, intervene and (re) create your city.

Keywords: Geography. City. Place. Teaching and Learning.

\section{INTRODUÇÃO}

Por que não aproveitar a experiência que têm os alunos de viver em áreas da cidade descuidadas pelo poder público para discutir, por exemplo, a poluição dos riachos e dos córregos e os baixos níveis de bem estar das populações, os lixões e os riscos que oferecem à saúde das agentes [...] Por que não discutir com os alunos a realidade concreta a que se deva associar a disciplina cujo conteúdo se ensina, a realidade agressiva em que a violência é a constante e a convivência das pessoas é muito maior com a morte do que com a vida? Por que não estabelecer uma 'intimidade' entre os saberes curriculares fundamentais aos alunos e a experiência social que eles têm como indivíduos? (FREIRE, 1996, p 30).

A escola constitui um espaço privilegiado no seio da sociedade moderna. Nela, a realidade deve ser associada às disciplinas escolares e os educandos podem aprender conteúdos diversos, como valores éticos e morais os quais devem pactuar as relações humanas do cotidiano e saberes significativos oriundos das disciplinas escolares formalmente estruturadas, visando ao preparo de cidadãos que possam compreender, intervir e reconstruir a sociedade humana. Todavia, nada adianta se esse processo evadir-se do contexto a que escola, alunos e professores estão inseridos, tampouco não propiciar reflexões que impliquem no repensar dessa realidade. Dessa forma, um ensino de qualidade e vinculado à realidade onde os atores da educação escolar vivenciam, demonstra aos educadores a importância da prática educativa fora dos muros da escola e também faz com que percebam que o ensino de Geografia contribui de forma significativa, pois através dele pode-se fazer uma leitura crítica da realidade.

Este estudo tem como objetivo destacar a importância de se considerar a cidade e o espaço de vivência dos alunos e professores como um palco fecundo que possibilite diversos matizes para o desenvolvimento do processo ensino e aprendizagem, além de destacar as concepções que os educadores possuem acerca da cidade de Formosa-GO como espaço da aprendizagem. 


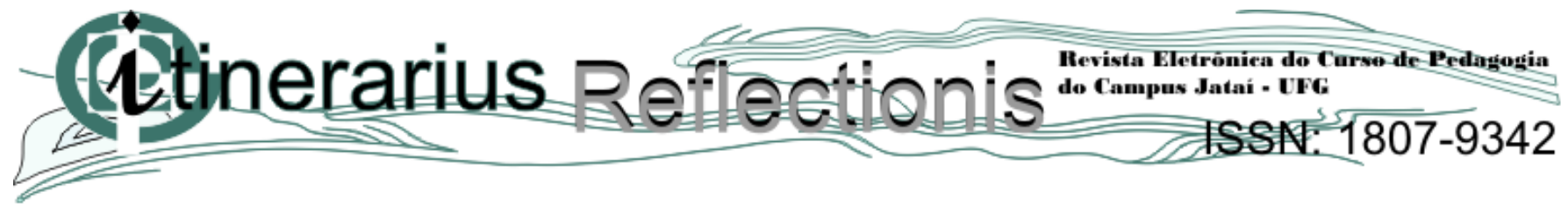

Trata-se de uma pesquisa de cunho exploratório, com abordagem qualitativa, em que lançou-se mão de um estudo de caso, qual seja, a realidade da cidade de Formosa-GO, bem como as percepções dos docentes acerca dos locais considerados educativos. Consoante Lüdke e André (2013), o estudo de caso é qualitativo e deve ser escolhido quando se pretende proceder a uma investigação de algo singular, de forma a enfatizar a interpretação do contexto e retratar a realidade de maneira ampla a partir de várias fontes de informação, por exemplo.

A coleta de dados que compõem este artigo proveio da reflexão do potencial educativo da cidade de Formosa-GO a partir de aporte teórico e também dos resultados da aplicação de questionários a nove professores de uma escola pública municipal.

\section{Geografia, Cidade e Lugar}

Segundo Callai (2000, p.55), "a geografia é uma ciência social. Ao ser estudada, tem que considerar o aluno e a sociedade em que vive". Acredita-se que considerar esse aspecto tanto no ensino de Geografia como em outras disciplinas, torna o processo de escolarização mais adequado à realidade em que os educandos estão inseridos.

Para Cavalcanti (2012) o ensino de Geografia contribui para a formação da cidadania por meio da prática de construção e reconstrução de conhecimentos, habilidades, valores que ampliam a capacidade de crianças e jovens compreenderem o mundo em que vivem e atuam, numa escola organizada como um espaço aberto e vivo de culturas. Nessa perspectiva, a cidade é compreendida como o lugar de vivência que pode ser aproveitada pelos professores em seus diversos espaços e tempo para a construção do conhecimento.

A cidade é educadora: ela educa, ela forma valores, comportamentos, ela informa com sua espacialidade, com seus sinais, com suas imagens, com sua escrita. Ela também é um conteúdo a ser apreendido por seus habitantes (CAVALCANTI, 2012, p.74).

Nesses pressupostos, a Geografia não se restringe ao simples fato de se localizar, mas se volta para a exploração do espaço da vida e dos homens como meio social. Assim, a cidade deve ser explorada para fins pedagógicos e sociais para que o aluno, conhecendo sua cidade, possa por ela ser educado. 


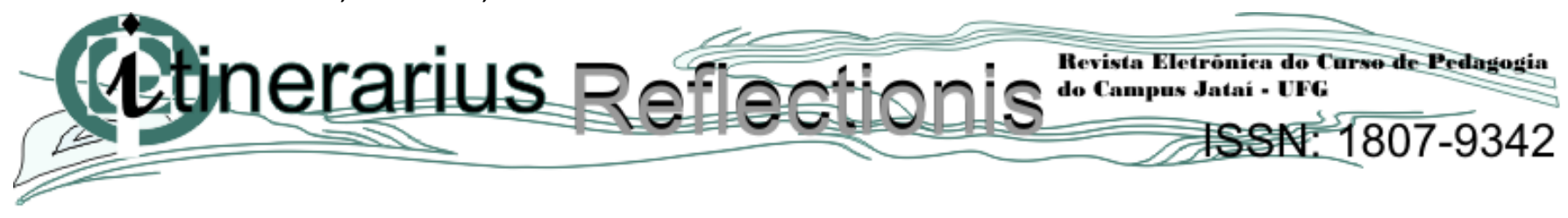

Castellar (2010, p.45) expõe que "a aprendizagem será significativa quando a referência do conteúdo estiver presente no cotidiano da sala de aula, quando se considerar o conhecimento que a criança traz consigo, a partir de sua vivência". Depreende-se que a Geografia, cidade e lugar unemse para se convergir em um aprendizado que não seja estanque, mas que faça parte do cotidiano vivido do aluno, sendo trabalhado o lugar na perspectiva de compreensão do espaço geográfico.

De acordo com Cavalcanti (2002):

[...] a cidade considerada conteúdo escolar, não é concebida apenas como forma física, mas como materialização de modos de vida, como um espaço simbólico, formador de sentidos de pertinência e de identidade fundamental para a formação da cidadania. Sendo assim seu estudo volta-se para desenvolver no aluno a compreensão do modo de vida da sociedade contemporânea e de seu cotidiano em particular. (p.75)

É bem factível que a cidade deve ser olhada enquanto espaço vivido do aluno e ser aproveitada do conhecimento que os alunos têm desse espaço para a realização de propostas educativas que possibilite a aprendizagem significativa do educando. Nota-se a grande necessidade de desfrutar dos espaços da cidade para a promoção de uma proposta pedagógica que esteja emaranhada na realidade dos próprios alunos.

São variados os espaços das cidades que possuem caráter socioeducativo, porém nem sempre explícitos. Portanto, será preciso que os professores estejam atentos e compreendam que por meio dos espaços vivenciados e experimentados pelos alunos no dia-a-dia é possível uma condução de aprendizagem significativa. Ao optar e valorizar tais espaços, os professores estarão contribuindo para inclusão dos estudantes no seu processo de aprendizagem, construindo conhecimentos.

Segundo Santos e Silveira (2011):

O território pode relevar as ações passadas e presentes, mas já congeladas nos objetos, e as ações presentes constituídas em ações, no primeiro caso, os lugares são vistos como coisas, mas a combinação entre ações presentes e ações passadas, às quais as primeiras trazem vida, confere um sentido ao que preexiste (p. 225).

Portanto, podemos explorar os fixos e os fluxos, os lugares e as paisagens do presente e do passado que se manifestam no território. Elementos que se constituem como memória viva de um povo que foi e que é. 


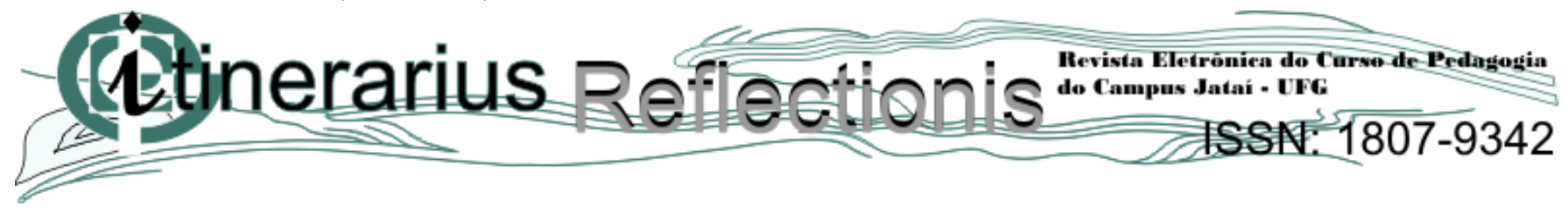

Nos escritos de Callai (1999) nota-se a preocupação com um ensino que esteja entrelaçado na realidade dos alunos, ou seja, um ensino que parta do lugar para a compreensão do mundo. Nesta perspectiva, o estudo do lugar vem sendo debatido por vários autores e em diferentes correntes metodológicas, cada uma contribuindo significativamente para a compreensão do lugar. Porém, a geografia humanística se constitui como corrente principal para o estudo da categoria lugar, pois valoriza os espaços cotidianos para a busca de aprendizagens.

Dessa forma, Callai (2000) apresenta o lugar como o espaço construído como resultado da vida das pessoas, dos grupos que nele vivem, das formas como trabalham, como produzem, como se alimentam e como fazem e usufruem do lazer, é a própria realidade. O lugar onde se vive caracterizado pela experiência e pelo mundo vivido.

Assim sendo, o lugar Formosa-GO com suas festas, festejos, manifestações culturais e religiosas, com belezas naturais exuberantes, a qual possui mais de 100.000 habitantes e 170 anos de história, mas também possui problemas e situações típicas de uma cidade que se desenvolve constitui um espaço que é vivido, logo, palco da vida que pode ser transformado em sala de aula.

Como por exemplo, a Mata da Bica, importante reserva natural no centro da cidade, resguarda uma belíssima fauna e flora de Mata de Galeria em volta de sua nascente, constituindo uma importante ferramenta para conscientização ambiental para a valorização do patrimônio natural que se mantém no perímetro urbano da cidade. Outros pontos turísticos de conservação ambiental, como Salto do Itiquira, Toca da Onça, Buraco das Araras, os lagos e lagoas urbanos (Lago do Vovô, Lago da Vovó, Lago do Abreu e Lagoa dos Santos), bem o córrego da cidade pode se tornar sala de aula, visto que, os alunos se aproximam da natureza, ajudam a conservar e ampliam sua consciência ambiental, principalmente como cidadão. Na Figura 1 pode-se observar a cidade de Formosa com alguns espaços destacados que podem ser convergidos ao processo de ensino. 

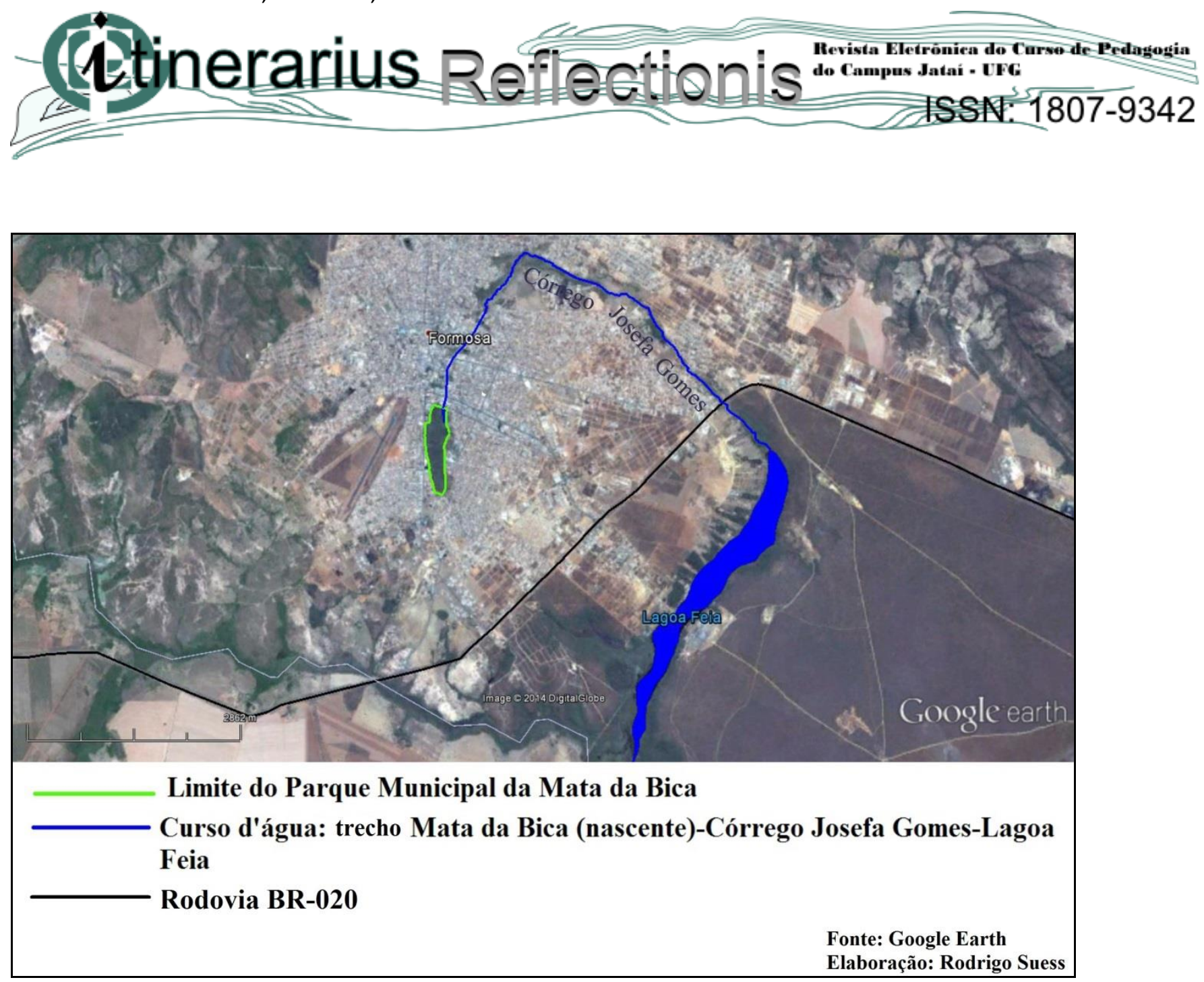

Figura 1 - Imagem de satélite disponibilizada pelo Google Earth, onde se encontra destacado o Parque Municipal Mata da Bica, Córrego Josefa Gomes, Lagoa Feia e a rodovia BR-020.

O córrego Josefa Gomes possui sua nascente no Parque Municipal da Mata da Bica e deságua na Lagoa Feia, ambos são tidos como pontos turísticos da cidade de Formosa. O córrego percorre uma expressiva parte da área urbana. Assim, o mesmo é importante elemento para se tratar as questões ambientais e urbanas da cidade. O professor poderá trabalhar também com ferramentas digitais, como o Google Earth, ferramenta essa, que contribui para a construção da imagem mais holística do objeto de estudo.

Assim, juntamente com os alunos, poderá identificar o crescimento da construção civil na cidade e seu o impacto no córrego e arredores; a construção de conjuntos habitacionais no decorrer do curso d'água (direito social da moradia x o direito ambiental); a falta de respeito em preservar as áreas de proteção permanente (APP) discutir sua importância e necessidade; o processo de assoreamento e eutrofização do 


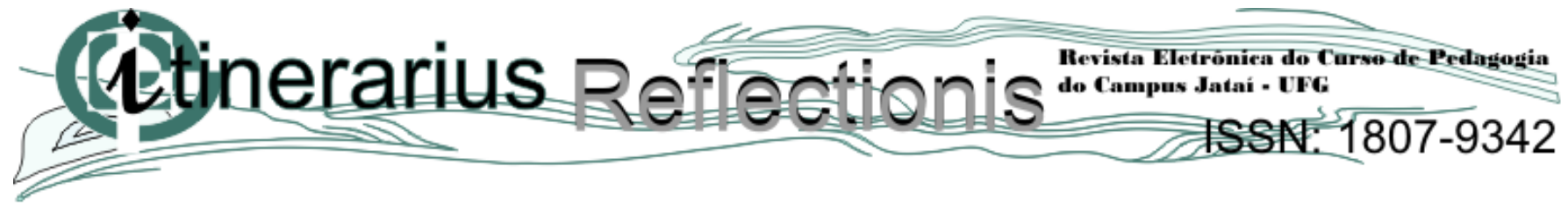

córrego e suas consequências ambientais; acúmulo de lixo e a proliferação de patógenos no córrego e entre outras questões geográficas que podem ser constadas in locu ou por meio de pesquisas propostas pelos professores. Os casarões históricos, o museu, o centro, a periferia e a expansão da construção civil são exemplos de estudo da Geografia na cidade.

O Lago do Vovô (Figura 2(a)) pode ser palco de aulas que visam discutir ações para fomentar a educação ambiental. A Rua Visconde Porto Seguro, Figura 2(b), localizada na área central da cidade, constitui local que sedia de diversos fenômenos geográficos. A concentração de lojas, bancos, empresas, os intensos fluxos de pessoas e mercadorias, dão grande importância econômica a essa rua que se torna um bom exemplo para ser abordado em sala de aula, pois envolve tramas do cotidiano dos alunos e ao mesmo tempo possui elementos urbanos e sociais, objetos de estudo da Geografia. Já o Museu dos Couros (Figura 2(c)) pode constitui-se num fecundo local para fomentar a discussão a respeito do histórico de formação, ocupação e exploração econômica no município de Formosa.

Por outro lado, mas não menos importante, a Barroquinha, comunidade que se auto identifica como um bairro ou setor, apesar de oficialmente pertencer ao Setor Nordeste, nos traz um espaço para discutir os problemas ambientais, de moradia, de distribuição de renda e descaso por parte do poder público, pois segundo Freire (1996) por que não aproveitar a experiência que têm os alunos de viver em áreas da cidade descuidadas pelo poder público para discutir, por exemplo, a poluição dos riachos e córregos e os baixos níveis de bem-estar das populações, os lixões e os riscos que oferecem a saúde das gentes.

É necessário usufruir esses ambientes urbanos para que as propostas educativas extramuros escolares sejam concretizadas. Mesmo ocorrendo restrição em conduzir os alunos a tais espaços, os educadores devem caminhar para a aplicação imediata dessas ações, onde educação cumpra seu papel, o de possibilitar, leitura e releitura do espaço vivido. 

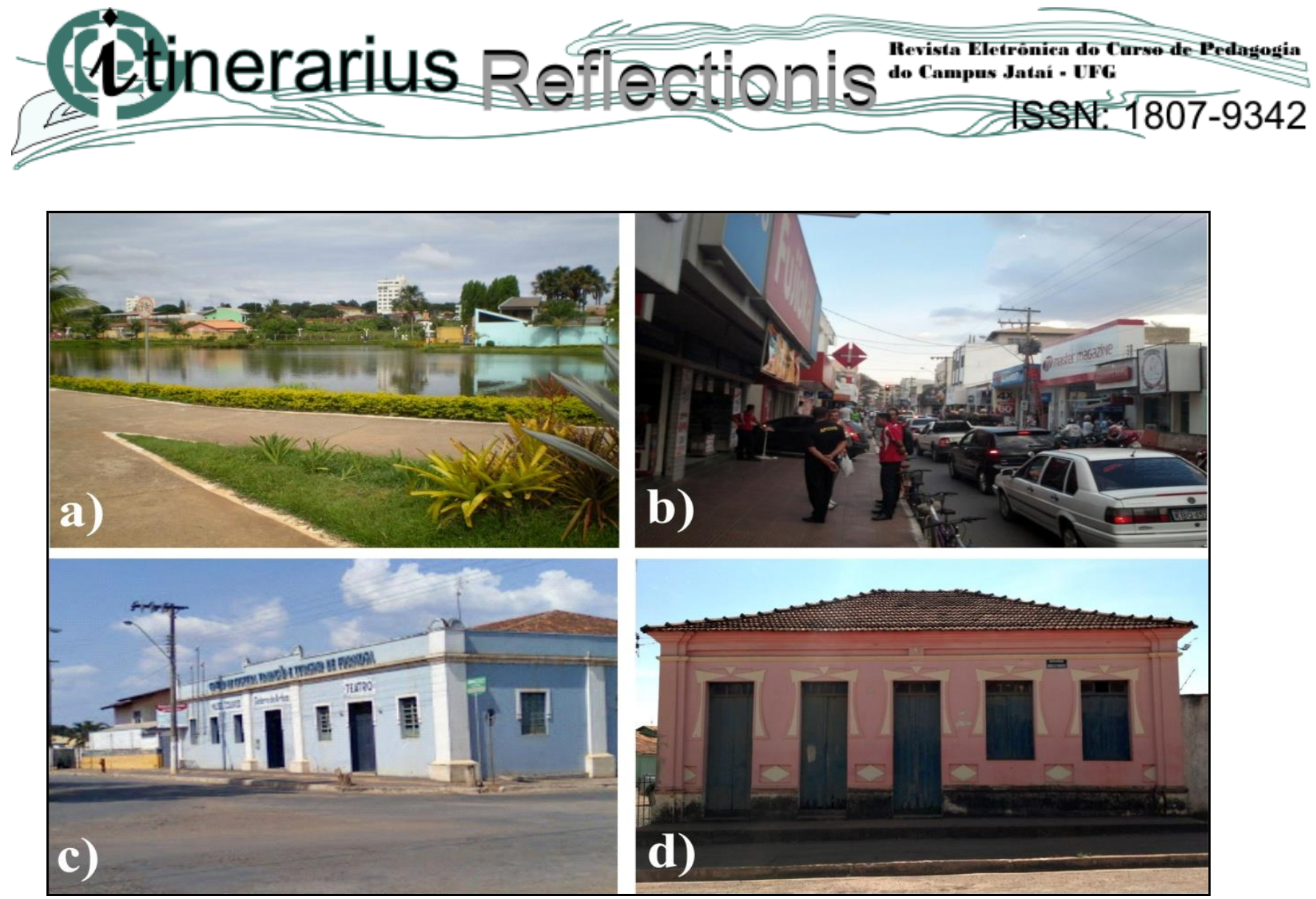

Figura 2- Outros exemplos de locais que podem ser aproveitados no processo ensino-aprendizagem. (A) Lago do Vovô. (B) A Rua Visconde Porto Seguro, localizada na área central da cidade. (C) Museu Couros (D) Casarão Antigo (Fotos dos Autores).

\section{Locais do munícipio de Formosa-GO que docentes consideram educativos}

Torna-se importante conhecer as concepções que os educadores têm acerca da cidade como possibilidade de aprendizagem, pois cabe aos docentes oportunizarem as condições e os instrumentos para que essa prática seja realizada. Assim, encontram-se nesta etapa as concepções dos educadores de uma escola do Município de Formosa-GO a respeito de locais que os mesmos consideram como educativos.

Para a coleta dessas concepções foram entregues questionários com dois questionamentos: (1) Professor, você poderia apontar locais, espaços da cidade de Formosa que tem o potencial para a realização de atividades educativas? (2) Caso você tivesse que realizar uma atividade educativa no(s) local(is) mencionado(s) acima como, em linhas gerais, procederia?

As respostas à pergunta 1 foram analisadas por meio do frequenciamento (porcentagem) dos espaços que os docentes consideram com potencial educativo cidade de Formosa. Na pergunta 2, optou-se por realizar uma síntese geral das ideias expostas. De acordo com as respostas dos docentes ao primeiro 
Primeiro semestre 2014, volume 1, número 16.

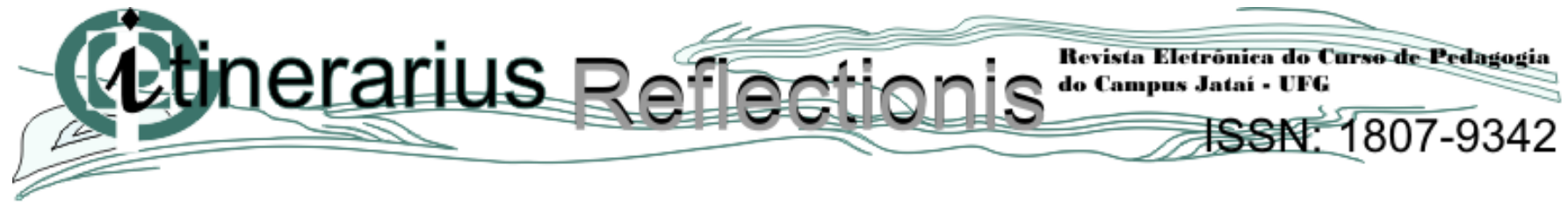

questionamento, 15 locais diferentes do município de Formosa-GO foram considerados com potencial educativo (Tabela 1).

Tabela 1 - Locais da cidade de Formosa-GO considerados educativos, segundo a ótica dos docentes pesquisados.

\begin{tabular}{lcc}
\hline Locais no município de Formosa-GO & Frequência absoluta & Frequência relativa \\
\hline Lagoa Feia & 04 & $14,81 \%$ \\
Parque Municipal do Itiquira & 04 & $14,81 \%$ \\
Mata Bica & 03 & $11,11 \%$ \\
Laguinho do Vovô & 03 & $11,11 \%$ \\
Museu dos Couros & 02 & $7,41 \%$ \\
Praça da Prefeitura & 02 & $7,41 \%$ \\
Caverna do Bisnau & 01 & $3,70 \%$ \\
Câmara Municipal & 01 & $3,70 \%$ \\
Lago do Abreu & 01 & $3,70 \%$ \\
Centro Olímpico do Bosque II & 01 & $3,70 \%$ \\
Saneago & 01 & $3,70 \%$ \\
Prefeitura Municipal & 01 & $3,70 \%$ \\
Parque do Indaiá & 01 & $3,70 \%$ \\
Lagoa dos Santos & 01 & $3,70 \%$ \\
Térrego Josefa Gomes & 01 & $3,70 \%$ \\
\hline Total & 01 & $300,00 \%$ \\
\hline
\end{tabular}

Fonte: Respostas dos professores ao questionário de pesquisa. 


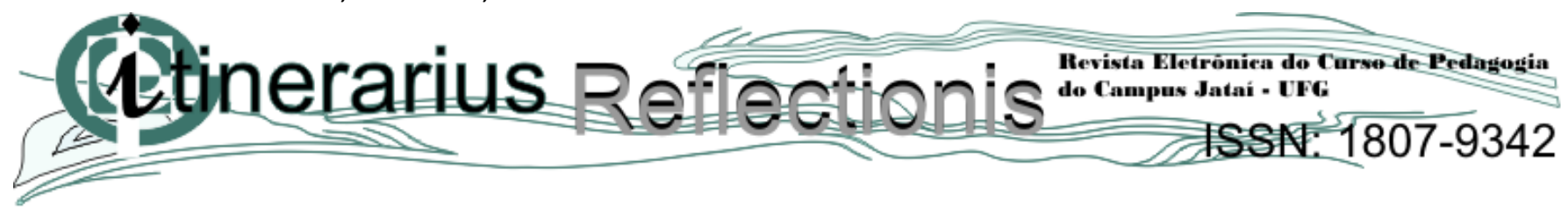

Com relação às repostas da questão 2 - Caso você tivesse de realizar uma atividade educativa no(s) local(is) mencionado(s) acima como, em linhas gerais, procederia? Observou-se que as repostas dos professores variaram conforme as suas perspectivas de ensino e disciplinas trabalhadas. Sintetizando as ideias, pode-se mencionar que os professores responderam dando ênfase em um aspecto específico. Podese citar a vinculação da saída de campo com a Educação Ambiental, com a análise histórica, análise da paisagem, valorização da diversidade local e exploração do espaço por meio da observação.

Para exemplificar selecionaram-se três repostas (Quadro 1: docentes 2, 3 e 5) que representam a perspectiva adotada pela maioria dos professores, assim sintetizamos as ideias expostas.

Quadro 1 - Respostas dos docentes à questão 2.

- Buscar fontes históricas: fotografias, documentos, reportagens, utensílios e outros recursos para enriquecer as aulas.

- Visitar os locais que iniciou a formação da cidade dos couros.

- Fazer uma linha do tempo (paralelo) desde o início da formação da cidade (docente 2).

- Salto do Itiquira - levaria os alunos para ver os tipos de paisagens, rios, rochas, vegetação, etc.

- Mata da Bica - Para os alunos perceberem as nascentes, os animais que habitam o local, etc.

- Lagoa Feia - Identificar a natureza e suas modificações feitas pelo homem.

- Teatro Municipal - Adquirir conhecimento através da arte e cultura (docente 3).

Com prudência para evitar problemas com os alunos, e realizaria lazer (docente 5)

Fonte: resultado da pesquisa realizada entre os professores.

Como se observa, os educadores têm a visão e a concepção que a cidade e seus diversos espaços podem ser convergidos em aprendizagem, no entanto estudos a respeito da cidade como possiblidade de espaço da aprendizagem ainda deve ser um campo a ser explorado. Na prática, ainda faltam muitos avanços para que essa perspectiva seja concretizada. Apesar de respostas positivas por parte dos professores, do reconhecimento de alguns locais que possibilitam aprendizagem no município de Formosa-GO, não garante que essas explanações foram concretizadas em ações. Em algumas repostas à segunda pergunta preocupam por apresentar respostas sem direcionamento e objetivo, o que poderia no caso de uma concretização dessas saídas a campo e uma saída para lazer e sem compromisso com a aprendizagem, no entanto, significativa parcela das respostas se apresentou positivas. 


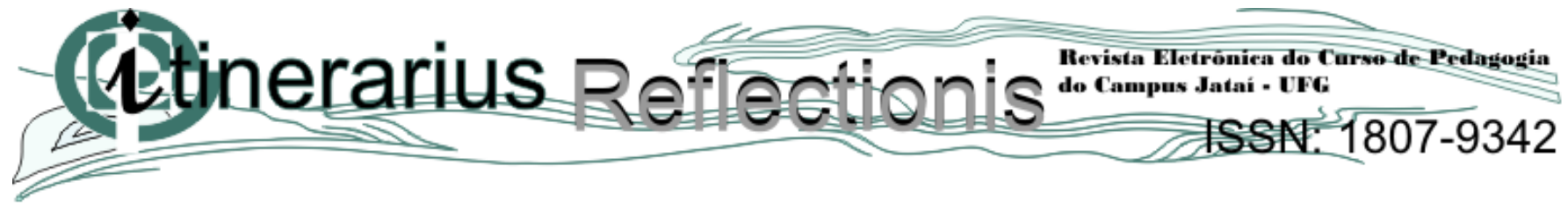

\section{CONSIDERAÇÕES FINAIS.}

A Geografia, cidade e lugar no processo de ensino-aprendizagem são importantes, pois se vinculam à leitura do espaço geográfico vivenciado e experimentado. Assim, os espaços educativos da cidade contribuem para o aprendizado de forma bastante dinâmica e propõe a relação entre os conteúdos ministrados nas salas de aula com os conhecimentos dos próprios alunos.

A sociedade (cidade) é parte permanente no ato de educar. O professor deve conduzir seus alunos e mediar os conhecimentos ensinados na perspectiva de irem ao encontro do mundo vivido dos educandos. Explorar espaços que rodeiam a escola, que são vistos pelos alunos do caminho de casa para escola, ou até mesmo distantes, levam as crianças a conhecerem, intervir e (re)criar a sua cidade.

Espera-se que os educadores, em especial, os de Geografia, reconheçam a partir dessas indagações e reflexões que o processo de ensino e aprendizagem não deve ficar limitado. Sua expansão vincula-se ao processo de busca pelo sucesso escolar, onde a educação deve ser articulada com a sociedade.

\section{REFERÊNCIAS BIBLIOGRAFICAS.}

CALLAI, H. Estudar o lugar para compreender o mundo. In: CASTROGIOVANNI, A. C. (Org.). Ensino de geografia:práticas e textualizações no cotidiano. Porto Alegre: Mediação, 2000.

CALLAI, H. C. O ensino de Geografia: recortes espaciais para análise. In: CASTRIGIOVANNI, A. C. et all. Geografia em sala de aula: práticas e reflexões. Porto Alegre: Ed. da Universidade, p. 56-60, 1999.

CASTELLAR, S. M. V. Educação Geográfica: Formação e didática. In: MORAIS, E. M. B.; MORAES, L. B. Formação de professores: conteúdos e metodologias no ensino de Geografia. Goiânia: Nepeg, 2010.

CAVALCANTI, L. S. Geografia e práticas de ensino. Goiânia: Alternativa, 2002. 
Primeiro semestre 2014, volume 1, número 16.

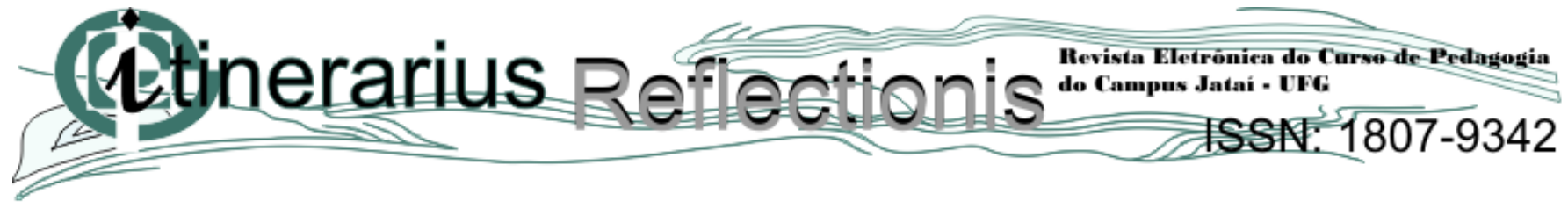

CAVALCANTI, L. S. A geografia escolar e a cidade: Ensaios de Geografia para a vida urbana cotidiana. Campinas, SP: Papirus, 2012.

FREIRE, P. Pedagogia da autonomia: saberes necessários à prática educativa. São Paulo: Paz e Terra, 1996 (Coleção Leitura), $146 \mathrm{p}$.

LÜDKE, M.; ANDRÉ, M. E. D. A. Pesquisa em educação: abordagens qualitativas. Rio de Janeiro: E. P. U. 2013.

SANTOS, M.; SILVEIRA, M. L. O Brasil: território e sociedade no início do século XXI. Rio de Janeiro: BestBolso, 2011. 
Primeiro semestre 2014, volume 1, número 16.

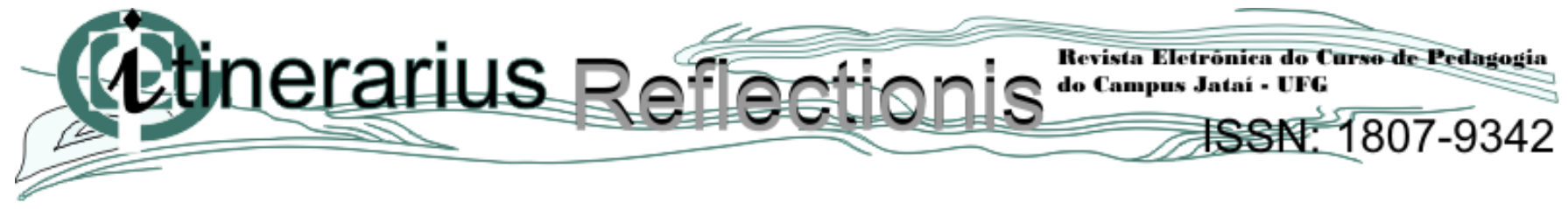

